\title{
Successful Esophageal Replacement Surgery in a 3-Year Old with Post-corrosive Esophageal Stricture
}

\author{
Cleopas Mutua Kaumbulu, ${ }^{1}$ Awori Mark Nelson, ${ }^{2}$ Rohini Patil, ${ }^{1}$ Ahmed Mohamed Rafik, ${ }^{2}$ James Ndung'u \\ Muturi $^{2}$
}

1.Gertrude's Children's Hospital

2.Kenyatta National Hospital

Correspondence to: Dr. Kaumbulu Cleopas; Email:cleomutua@gmail.com.

\begin{abstract}
Summary
Accidental caustic ingestion in children, though entirely preventable, continues to be present in developing countries. Gastrointestinal injuries following caustic ingestion in children range from mild to fatal. Presentation of such children to the medical facility could be early or sometimes late with complications. Management is based on the type of injury and could range from medical conservative management to complex surgical procedures. Such complex surgeries are almost unavailable in developing countries. We present a 3-year old who presented to our facility with an esophageal stricture following accidental caustic ingestion four months prior to presentation. He had a failed stricture
\end{abstract}

dilatation and needed to be managed surgically; he subsequently had a good outcome, which is rare in developing countries.

Keywords: Post-corrosive esophageal stricture, Esophageal replacement surgery

Ann Afr Surg. 2020; 17(2):80-84

DOI: http://dx.doi.org/10.4314/aas.v17i2.9

Conflicts of Interest: None

Funding: None

(C) 2020 Author. This work is licensed under the Creative Commons Attribution 4.0 International License.

\section{Introduction}

Accidental caustic ingestion in children is a worldwide problem (1), but most of the cases are unreported and the true incidence of the condition is not known (2). A wide range of gastrointestinal injuries result following ingestion of caustic substances; the degree of injury depends on the nature, concentration and quantity of the caustic ingestion. Esophageal stricture is one of the complications in children who present late. These strictures are managed by endoscopic dilatation with balloon or using rigid savary bougies. If these fail, surgery in the form of esophageal replacement using stomach or colonic interposition should be considered. Mortality and morbidity following surgery are low in expert hands (3). Late reconstructive surgeries in children with a reportable good outcome are rare in developing countries.

\section{Case report}

A 3-year-old boy was suspected to have swallowed a corrosive substance four months prior to admission. Following consumption, he was irritable and had increased secretions and coughing. He had been admitted twice in a local medical facility, where he was stabilized and treated with intravenous fluids and antibiotics for the oral sores. A chest x-ray at that point was unremarkable. Endoscopy showed erosions of the esophagus and the stomach. Upon discharge he developed progressive dysphagia. He was started on proton pump inhibitors for 2 weeks, with no improvement. A barium swallow showed features suggestive of spastic esophagitis. A repeat barium swallow three months later showed features of post-corrosive esophagitis with a tight esophageal stricture $7 \mathrm{~cm}$ along distal esophagus. The child was referred to our facility, Gertrude's Children's Hospital. He underwent esophageal dilatation, following which he developed esophageal rupture. The child had increasing respiratory distress by now. A chest x-ray showed subcutaneous emphysema in the neck and pneumomediastinum and bilateral pleural effusion (Fig.1). Barium studies confirmed features suggestive of esophageal rupture (Fig. 2). By this time, the child needed oxygen via nasal prongs and inotropes to support the blood pressures. Considering the general condition of the patient, the decision was made for esophageal diversion surgery and gastrotomy. A left cervical end esophagostomy was performed and the esophagogastric junction was banded twice with 6-mm nylon tape at the time the gastrostomy tube was inserted. The child 
tolerated the procedure well and was stabilized in the intensive care unit. Feeds were initiated through gastrostomy and the child was subsequently discharged. Three months later, the child was reviewed in readiness for esophageal replacement using colon as a conduit. Preoperative bowel preparation was done. Under general anesthesia, the cervical esophagostomy was mobilized via old neck incision (Fig. 3), through a laparotomy. Ascending, transverse and descending colon were mobilized (Fig. 4); most of the transverse colon and distal $4 \mathrm{~cm}$ of ascending colon was used as conduit (Fig. 5) on a left colonic artery pedicle and retro sternal space developed bluntly from above and below (Fig. 6). The closed end of colon was delivered into neck (isoperistaltic) via retrosternal space, esophagus spatulated along anterior border then anastomosed endto-side to posterior aspect of colon (Fig. 7).

Nasogastric tube was passed into stomach and secured, without changing the gastrostomy site. The child was again received at the intensive care unit intubated.

Feeds were initiated through the nasogastric tube, initially as continuous feeds then slowly changed to bolus feeds. Later the nasogastric tube was removed and the boy was allowed to feed orally and was discharged. The child's progress was followed-up four months after the surgery. He was feeding and growing well. He will be kept under regular follow-up.

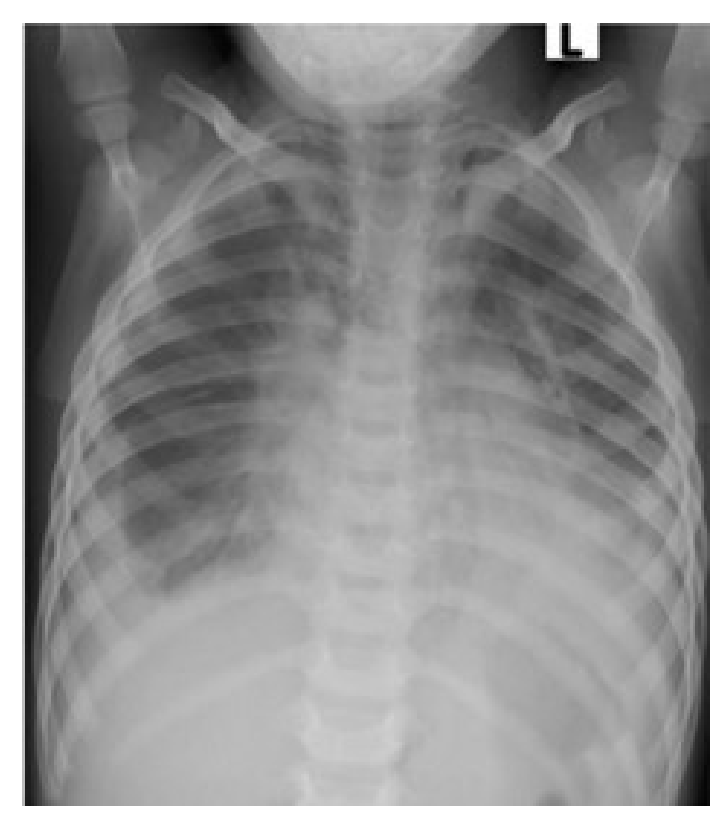

Figure 1: Chest $\mathrm{x}$-ray after esophageal dilatation showing air in the mediastinum

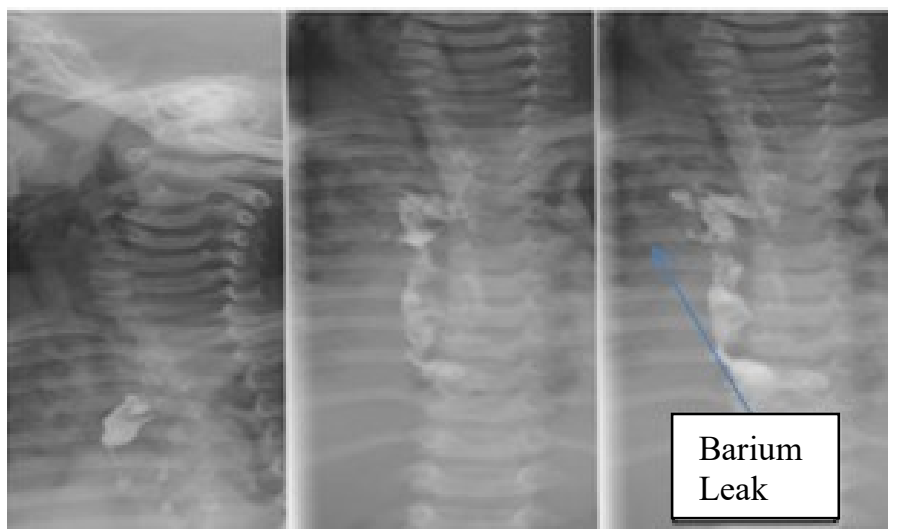

Figure 2: Barium studies showing features of esophageal rupture

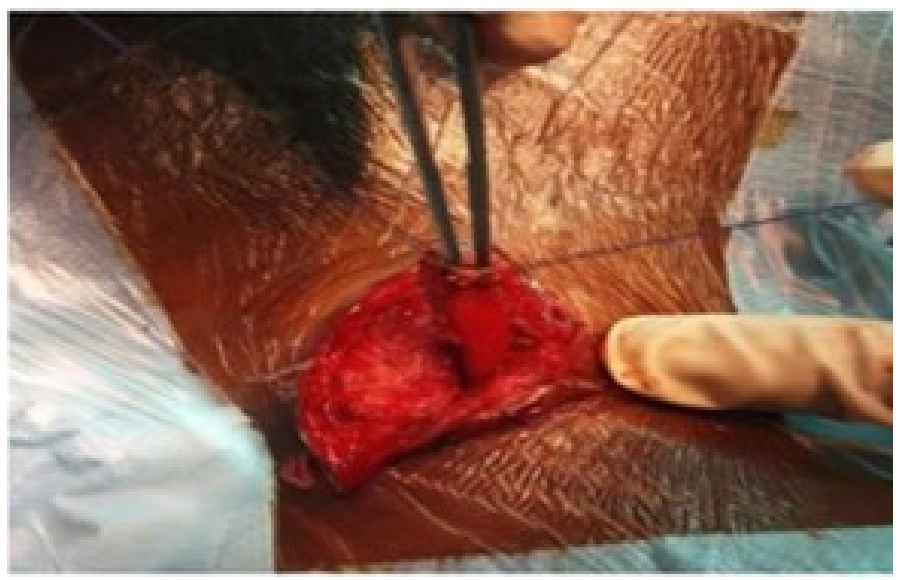

Figure 3: Esophageal diversion surgery

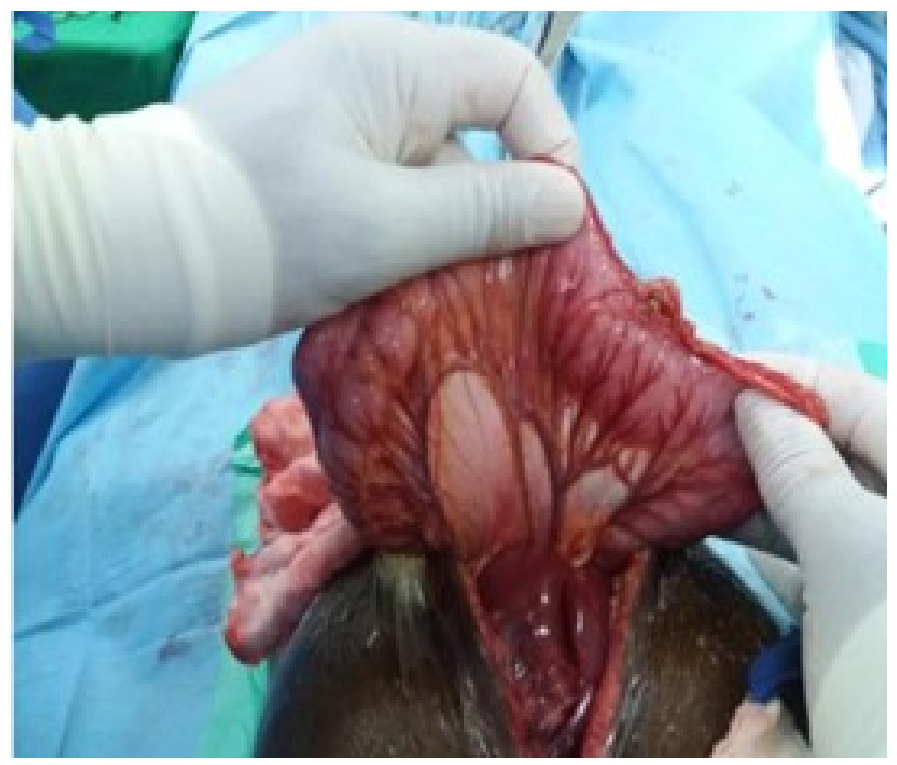

Figure 4: Mobilizing the colon for conduit. 


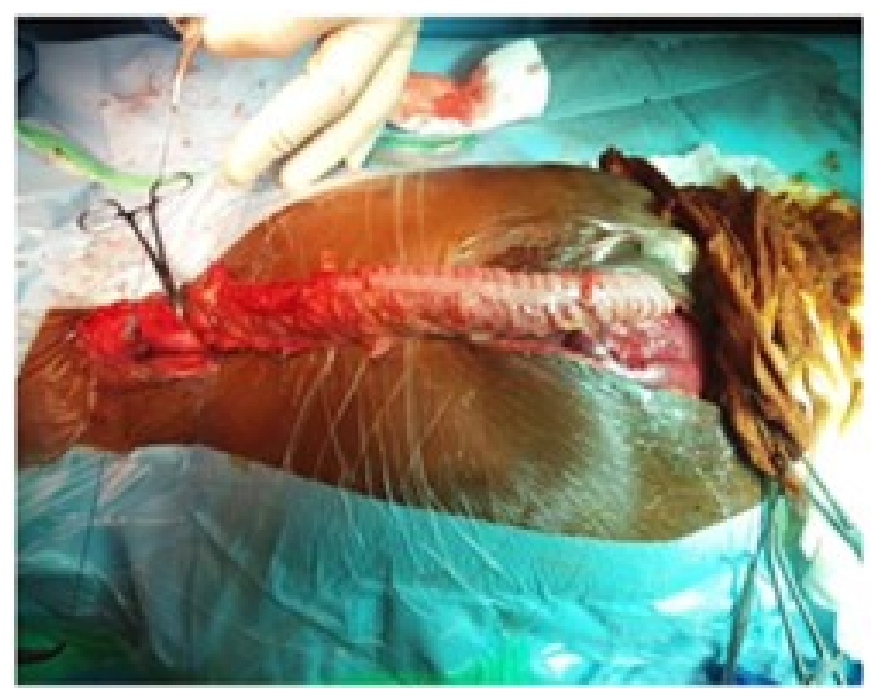

Figure 5: Measuring length of colon for conduit

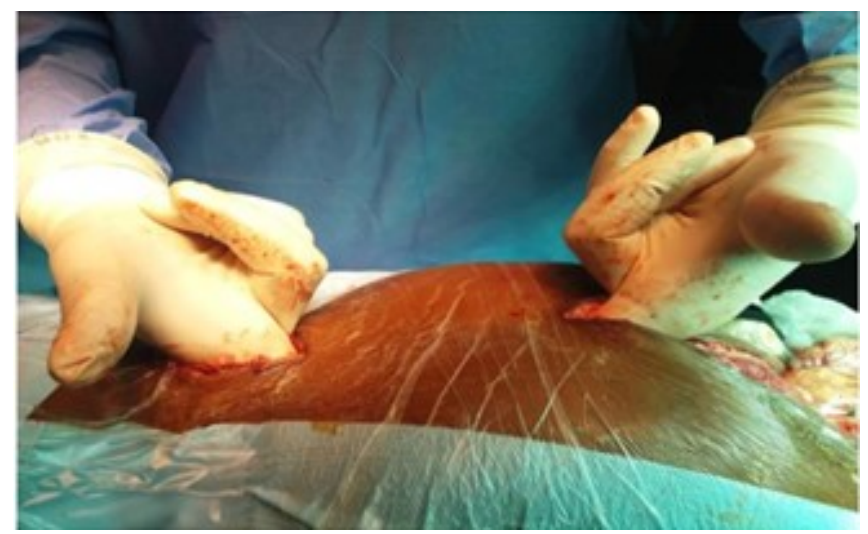

Figure 6: Creating retrosternal tunnel

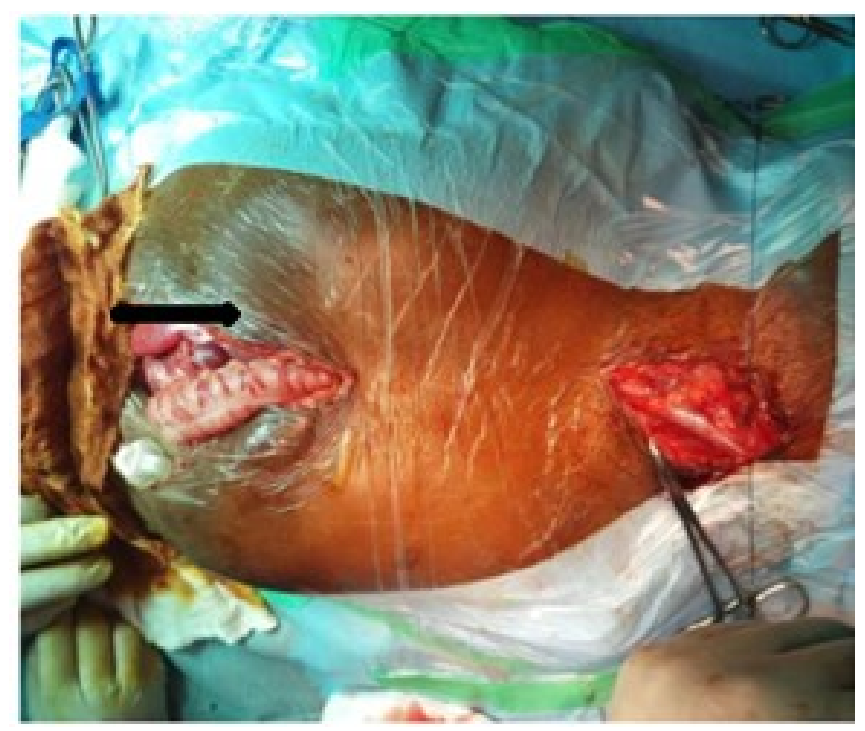

Figure 7: Colon in retrosternal position (black arrow)

\section{Discussion}

The incidence of accidental caustic ingestion in children in developing countries is high, because prevention is lacking. The problem is largely unreported in these settings (2). The average age of children with accidental caustic ingestion in Africa was 3.07 \pm 2.02 years (range $1.8-5.4$ years), 75 males $(0.91 \%)$ and 19 females $(0.23 \%)$ with (F/M ratio, 1:4). In Africa, of children exposed to caustic substances, $33 \%$ of accidents were caused by alkaline agents and $33 \%$ by acidic agents (4).

Acids cause coagulation necrosis, with eschar formation that may limit substance penetration and injury depth. Alkalis combine with tissue proteins and cause liquefactive necrosis and saponification, and penetrate deeper into tissues, causing extensive tissue damage.

The degree of a corrosive lesion depends on the nature, concentration, and quantity of the caustic substance ingestion. Determining the severity of damage following caustic substance ingestion is one of the most important initial steps for treatment and for preventing complication. The symptoms may not ascertain the severity of the injury. Early manifestations are nausea, abdominal pain, vomiting, and dyspnea. Later manifestations include fever, tachycardia, tachypnea, and dysphasia. The presence of three or more symptoms is an important predictor of severe esophageal lesions (5). In children, $18 \%$ to $46 \%$ of all caustic ingestions are associated with esophageal burns. The incidence of coexistent gastric injury in the literature ranges from $20 \%$ to as high as $62.5 \%$ (6). Esophageal stricture is considered a short-term effect, but esophageal perforation, esophageal obstruction and cancer could be some of the long-term effects of ingesting caustic agents. In the initial management, laboratory studies like total white cell counts and $\mathrm{C}$ reactive proteins are useful in monitoring and guiding patient management.

Shortly after ingestion, a plain chest radiograph may reveal pneumomediastinum, suggesting esophageal perforation, as well as free air under the diaphragm, indicating gastric perforation. Hypaque or gastrograffin studies are useful options to confirm the above. A computerized tomography scan likely offers a more detailed evaluation than early endoscopy about the transmural damage of esophageal and gastric walls and the extent of necrosis (7).

Endoscopy is important in the management of caustic ingestion. Every child with suspected caustic ingestion and symptoms/signs (any oral lesions, vomiting, drooling, dysphagia, hematemesis, dyspnea, abdominal 
pain, etc.) should have an endoscopy within 24 hours of ingestion to identify all the consequent digestive tract lesions. The risk of severe damage increases proportionally with the number of signs and symptoms, and an endoscopy is always mandatory in symptomatic patients. It can be withheld if the child is asymptomatic and if adequate follow-up is assured.

Findings on endoscopy are graded as follows:

Grade 0 -a normal mucosa

Grade 1 -only slight swelling and redness of the mucosa

Grade 2A-presence of superficial ulcers, bleeding, and exudate

Grade 2B -local or encircling deep ulceration

Grade $3 \mathrm{~A}$-focal necrosis

Grade 3B -extensive necrosis

Most patients with grade 1 or $2 \mathrm{~A}$ injuries have good prognosis (8).

In the medical line of management, the use of steroids was controversial. Different steroids (dexamethasone, prednisolone, methyl-prednisolone) are used at different doses and through different routes of administration (oral, intravenous) from 7 days to 4-6 weeks in children with corrosive esophagitis. High-dose methylprednisolone used to manage grade $2 \mathrm{~B}$ esophageal burns may reduce stricture development (9). Intralesional steroid injections increase efficacy of bougie dilation and decrease the need to repeat it (10).

Administration of broad-spectrum antibiotics is usually advised mainly if corticosteroids are initiated, as well as if lung involvement is identified.

Mitomycin C, a chemotherapeutic agent with DNA crosslinking activity, when injected or applied topically to the esophageal mucosa, significantly reduced the number of dilatation sessions needed to alleviate dysphagia in patients with caustic esophageal strictures. However, long-term follow-up is needed to prove its efficacy and to evaluate potential long-term side effects (11).

Surgical intervention is indicated when attempted dilatation either causes esophageal perforation or fails to relieve stenosis. As esophageal strictures caused by corrosive injury are usually long, dilatation often is unsuccessful and some form of esophageal replacement surgery will be required. When surgery is indicated, the best solution is usually emergent (or urgent) external diversion of the esophagus via a cervical stoma (esophagostomy), and the insertion of a gastrostomy tube for feeding. Attempts to repair perforations or replace the esophagus at this time are ill advised as the patient usually is not in an optimal condition. With esophageal diversion, a useful procedure, particularly in sick patients, is to band (tie-off) the gastro-esophageal junction (twice) with 3-mm nylon tape (as opposed to transecting it). The tape is tied tight enough to occlude the esophageal lumen but not to totally occlude blood supply to the esophageal wall.

With esophageal replacement, several alternatives are available that offer the chance of a good quality of life for a prolonged period; none, however, are as good as the native esophagus. Replacement surgery should be performed once a patient's nutritional status has returned to normal (at least 3 months after starting gastrostomy feeds). Replacement conduits can be fashioned from the stomach, colon or jejunum. Available evidence shows that gastric (that uses the whole stomach) and colonic conduits are the most favored (12). Colonic conduits are more complex to fashion than gastric conduits but have less reflux. In addition, colonic conduits occupy less space in the chest than gastric conduits and so are associated with less respiratory complications. Thus, the colon is considered the optimal conduit (12). It may be placed retrosternally or in the posterior mediastinum. It is usually placed in an isoperistaltic orientation, and an antireflux procedure is not generally indicated when it is placed retrosternally. We normally place a nasogastric tube intraoperatively and aim to retain the feeding gastrostomy for 3 months postoperatively (we remove it once we are satisfied with the quality of swallowing). In the immediate postoperative period, we do not feed the patient for 7 days, and then we perform a water-soluble contrast study on day 8 . If there is no leak, we commence oral feed. Cervical leak is quite common in the immediate postoperative period; most leaks are small and will heal spontaneously (12). We keep the patient 'nil per oral' until cervical leaks are healed, but we feed the patient through the gastrostomy tube. We keep the nasogastric tube in-situ until the cervical leak has healed.

\section{Conclusion}

Esophageal replacement offers a robust solution to dysphasia resulting from caustic injury to the esophagus. The procedure can be performed with a relatively low risk of early mortality. The isoperistaltic colon is probably the best choice of conduit in children.

\section{Acknowledgement}

To Gertrude's Hospital's intensive care unit, theatre team, and radiology and pathology departments. 


\section{References}

1. Pearn J, Nixon J, Ansford A, et al. Accidental poisoning in childhood: Five-year urban population study with 15 -year analysis of fatality. Br Medical J (Clin Res Ed.) 1984; 288(6410):44-6.

2. Ekpe EE, Ette V. Morbidity and mortality of caustic ingestion in rural children: Experience in a new cardiothoracic surgery unit in Nigeria. ISRN Pediatrics 2012; (2012): 210632.

3. Chirica M, Veyrie N, Munoz-Bongrand N, et al. Late morbidity after colon interposition for corrosive esophageal injury: Risk factors, management, and outcome. A 20 -year experience. Ann Surg 2010; 252: 271-80.

4. Rafee M, Ghojadeh M, Mehdizadeh A, et al.

5. Intercontinental comparison of caustic ingestion in children. Korean J Pediatr. 2015; 58(12):491-500.

6. Salzman M, O'Malley R. Updates on the evaluation and management of caustic exposures. Emerg Med Clin North Am. 2007; 25(2):459-76.

7. Zargar S, Kochhar R, Nagi B, et al. Ingestion of strong corrosive alkalis: Spectrum of injury to upper gastrointestinal tract and natural history. Am J Gastroenterol. 1992; 87:337-41.

8. Skucas J. Contrast media. In: Gore R, Levine M, Laufer I, Textbook of gastrointestinal radiology. Philadelphia: WB Saunders, 2000: 2-14

9. Thomson M, Tringali A, Dumonceau J, et al. Paediatric gastrointestinal endoscopy: European Society for Paediatric Gastroenterology Hepatology and Nutrition and European Society of Gastrointestinal Endoscopy Guidelines. J Pediatr Gastroenterol Nutr. 2017; 64:133-53.

10. Usta M, Erkan T, Cokugras F, et al. High doses of methylprednisolone in the management of caustic esophageal burns. Pediatrics 2014; 133: E1518-24.
11. Kochhar R, Ray JD, Sriram PV, et al. Intralesional steroids augment the effects of endoscopic dilation in corrosive esophageal strictures. Gastrointest Endosc. 1999; 49:509-13.

12. Berger M, Ure B, Lacher M. Mitomycin C in the therapy of recurrent esophageal strictures: Hype or hope? Eur J Pediatr Surg. 2012; 22:109-16.

13. Lui J, Yang Y, Zheng C, et al. Surgical outcomes of different approaches to esophageal replacement in long-gap esophageal atresia: A systematic review. Medicine (Baltimore). 2017; 96:21(e6942)

14. AngottiR, Molinaro F, Noviello C, et al. Gastric transposition as a valid surgical option for esophageal replacement in pediatric patients: Experience from three Italian medical centers. Gastroenterol Rep (Oxf). 2017; 5(1):47-51.

15. Munkonge L. Challenges in the management of benign oesophageal strictures in Zambians. East and Central African Journal of Surgery. 2006; 11(2):72-7.

16. Contini S, Tesfaye M, Picone P, et al. Corrosive esophageal injuries in children. A short-lived experience in Sierra Leone. Int J Pediatr Otorhinolaryngol. 2007; 71(10):1597-604.

17. Saula P, Kuremu R. Esophageal replacement for long-gap esophageal atresia in a resource-limited setting. Ann Afr Surg. 2015; 12(2):104-8.

18. Boume M, Adabra K, Amavi A, et al. Management of the caustic stenosis of the esophagus in children: Six years' experience in a developing country (Togo). SM J Pediatr Surg. 2017; 3(1):1038

19. Hamza A, Abdelhay S, Sherif H, et al. Caustic esophageal strictures in children: 30 years' experience. J Pediatr Surg. 2003; 38(6):828-33. 